\title{
Hubungan Morfologi Plak pada Stenosis Arteri Karotis Ekstrakranial dengan Kejadian Stroke Iskemik
}

\author{
Dedi Sutia ${ }^{1}$, Syarif Indra ${ }^{1}$, Hendra Permana ${ }^{1}$, Lenny Arinda $^{2}$, Afriyeni Sri Rahmi ${ }^{2}$
}

\begin{abstract}
Abstrak
Stenosis arteri ekstrakranial bermanifestasi dalam berbagai kondisi, mulai dari asimptomatik hingga stroke iskemik. Salah satu modalitas diagnostik untuk mengevaluasi gambaran stenosis tersebut adalah carotid duplex. Terdapatnya plak pada stenosis arteri ekstrakranial mempengaruhi kejadian stroke iskemik. Namun masih belum jelas hubungan antara morfologi plak pada stenosis arteri ekstrakranial dengan kejadian stroke iskemik. Tujuan: Menentukan hubungan morfologi plak pada stenosis arteri karotis ekstrakranial dengan kejadian stroke iskemik. Metode: Penelitian ini merupakan studi analitik dengan desain cross sectional yang dilakukan pada 20 orang sampel pada bulan Januari hingga September 2018 di RSUP Dr M Djamil, Padang. Kriteria inklusi adalah pasien yang telah didiagnosis stenosis arteri ekstrakranial dengan plak dari pemeriksaan carotid duplex dan kriteria eksklusi adalah pasien yang tidak datang kontrol atau tidak bisa dihubungi. Hubungan antar variable diuji dengan uji Chi-square. Hasil dianggap bermakna secara statistik jika nilai $p<0,05$. Hasil: Sebanyak 12 orang (60\%) sampel adalah perempuan dan 8 orang (40\%) adalah laki-laki. Median umur sampel adalah 56 tahun (37-71 tahun). Morfologi plak berupa plak nonulcerated sebanyak 11 orang (55\%) dan plak ulcerated sebanyak 9 orang (45\%). Kejadian stroke iskemik ditemukan sebanyak 9 orang (45\%) dan tidak stroke sebanyak 11 orang (55\%). Terdapat hubungan antara morfologi plak pada stenosis arteri ekstrakranial dengan kejadian stroke iskemik $(p=0,02)$; $R R=5$. Simpulan: Terdapat hubungan bermakna antara morfologi plak pada stenosis arteri ekstrakranial dengan kejadian stroke iskemik.
\end{abstract}

Kata Kunci: morfologi plak, stenosis arteri ekstrakranial, stroke iskemik

\begin{abstract}
Extracranial arterial stenosis manifests in a variety of conditions, from asymptomatic to ischemic stroke. One of diagnostics modality for evaluating this stenosis is a carotid duplex. The presence of plaque in extracranial artery stenosis affects ischemic stroke. It is still unclear about the association between plaque morphology in extracranial artery stenosis and ischemic stroke. Objectives: To determined the correlation between plaque morphology in extracranial artery stenosis and ischemic stroke. Methods: This study was an analytic study with cross-sectional design on 30 samples on January until September 2018 in RSUP Dr M Djamil. The inclusion criteria were patients who have diagnosed with extracranial artery stenosis with a plaque from the carotid duplex examination and the exclusion criteria were patients who did not come to control or can not be contacted. The association among variables used chisquare test. The result is considered significant if the value of $p<0.05$. Results: There were 19 samples (63,3\%) female and 11 samples (36,7\%) were male. The age median was 57 years old (22-77 years old). Plaque Morphology consist of nonulcerated plaque was 12 samples (40\%), and ulcerated plaque is 18 samples (60\%). Ischemic stroke was found in 17 samples (40\%), and non-stroke was 13 samples (60\%). There was a correlation between the plaque morphology in extracranial arterial stenosis with ischemic stroke $(p=0.01) ; R R=5$. Conclusion: There was a significant correlation between plaque morphology in extracranial arterial stenosis and stroke outcome.
\end{abstract}

Keywords: extracranial arterial stenosis, ischemic stroke, plaques morphology

Affiliasi penulis: ${ }^{1}$ Bagian Neurologi, Fakultas Kedokteran, Universitas Andalas, Padang, Inodonesia. ${ }^{2}$ Program Pendidikan Dokter Spesialis Neurologi, Fakultas Kedokteran, Universitas Andalas, Padang, Indonesia.
Korespondensi: Dedi Sutia, Email: dr.dedisutia@gmail.com Telp/HP: 081274606715. Alamat: Jalan Perintis Kemerdekaan No. 94, 25127, Padang, Indonesia. 


\section{PENDAHULUAN}

Stenosis arteri ekstrakranial bermanifestasi dalam berbagai kondisi, mulai dari asimptomatik hingga stroke iskemik. Stenosis ekstrakranial merupakan suatu penyakit yang dinamis, kondisinya berubah dalam kejadian gangguan vaskular, dan umum terjadi pada seluruh populasi dunia, terutama pada populasi asia. Stenosis arteri intrakranial diperkirakan terjadi pada $33 \%-50 \%$ penderita stroke setiap saat dan membawa risiko gejala stroke iskemik. ${ }^{1,2}$ Pemberian terapi medikamentosa meskipun terbukti telah berhasil menurunkan tingkat stroke, namun tidak secara konsisten dapat mencegah perkembangan penyakit. Hasil penelitian prospektif baru-baru ini menunjukkan bahwa ada beberapa faktor yang perlu dipertimbangkan dalam menilai kejadian stroke iskemik pada stenosis arteri ekstrakranial, yaitu plak ulcerated, progresifitas stonosis, dan gejala klinis stroke iskemik sebelumnya. ${ }^{2,3,4}$

Salah satu modalitas diagnostik untuk mengevaluasi gambaran stenosis arteri ekstrakranial adalah carotid duplex, suatu modalitas diagnostik noninvasif dan minimal radiasi yang digunakan untuk menilai morfologi plak dan derajat stenosis dengan menggunakan gelombang ultrasound., ${ }^{1,5,6}$ Morfologi plak ditentukan oleh tiga hal, yaitu efek hemodinamik (persentase stenosis yang diakibatkan), eksogenitas (hipo atau hiperskoik) yang ditentukan oleh telah terjadi atau tidaknya proses kalsifikasi, dan permukaan plak (ulcerated dan nonulcerated). ${ }^{1}$ Plak ulcerated memiliki kecenderungan untuk ruptur, yang menyebabkan pembentukan trombus dan embolisasi yang berujung pada stroke iskemik. .,6,7,8

Faktor risiko stroke iskemik pada stenosis arteri ekstrakranial menjadi topik yang banyak diperbincangkan dalam berbagai literatur terbaru. Berbagai biomarker dan teknik untuk mengidentifikasi faktor-faktor ini telah diteliti. Bahkan, semua studi yang dilakukan menunjukkan hubungan antara parameter yang diteliti dengan resiko stroke iskemik, yang akurat, tetapi juga masih terdapat hasil yang bias. Literatur yang tersedia menunjukkan bahwa morfologi plak memiliki peran penting dalam mengidentifikasi resiko stroke iskemik. ${ }^{9,10,11,12}$ Hasil penelitian Muscari et al (2016), morfologi plak tidak memiliki hubungan dengan stroke iskemik pada stenosis arteri ekstrakranial, melainkan adalah derajat stenosis itu sendiri. ${ }^{13}$

Perbedaan hasil yang ditemukan dari penelitian sebelumnya mengenai topik ini menyebabkan hubungan antara morfologi plak pada stenosis arteri ekstrakranial dengan kejadian stroke iskemik masih belum jelas. Oleh karena itu penulis tertarik untuk melakukan penelitian mengenai hubungan antara morfologi plak pada stenosis arteri ekstrakranial dengan kejadian stroke iskemik. ${ }^{13,14,15,16}$

Tujuan dari penelitian ini adalah untuk mengetahui hubungan antara morfologi plak nonulcerated dan ulcerated pada stenosis arteri ekstrakranial dengan kejadian stroke iskemik.

\section{METODE}

Penelitian ini adalah studi analitik dengan desain cross-sectional. Penelitian dilaksanakan di RSUP DR. M. Djamil, Padang pada Bulan Januari hingga September 2018.

Populasi dalam penelitian ini adalah semua pasien yang sudah didiagnosis stenosis arteri ekstrakranial dengan pemeriksaan carotid duplex di RSUP M. Damil Padang dan tidak memiliki riwayat stroke sebelumnya. Sampel dalam penelitian ini diambil dari populasi yang memenuhi kriteria inklusi. Kriteria inklusi sampel adalah pasien yang telah didiagnosis stenosis arteri ekstrakranial dengan plak dari pemeriksaan carotid duplex dan tidak memiliki riwayat stroke sebelumnya. Kriteria eksklusi adalah pasien yang tidak datang kontrol ke RSUP M. Djamil atau tidak bisa dihubungi selama penelitian berlangsung. Data dikumpulkan dari rekam medik pasien yang sudah didiagnosis stenosis arteri ekstrakranial dengan pemeriksaan carotid duplex di RSUP M. Damil Padang dan tidak menderita stroke di awal penelitian dengan jumlah sampel 20 orang.

Analisis data dilakukan dengan cara bertahap yaitu analisis univariat kemudian bivariat secara komputerisasi. Analisis univariat dilakukan untuk mengetahui gambaran distribusi dan frekuensi dari variabel independen (morfologi plak) dan variabel dependen (kejadian stroke iskemik). Analisis bivariat untuk melihat hubungan variabel independen dengan variabel dependen menggunakan uji Chi-square, jika 
$\mathrm{p}<0,05$ terdapat hubungan yang signifikan antara variabel independen dan variabel dependen.

\section{HASIL}

Penelitian dilakukan terhadap 20 orang pasien, sebagian besar adalah perempuan (60\%). Median umur sampel adalah 56 tahun (37-71 tahun). Pada pemeriksaan carotid duplex didapatkan morfologi plak berupa plak nonulcerated sebanyak 11 orang (55\%) dan plak ulcerated sebanyak 9 orang (45\%). Selama penelitian ditemukan kejadian stroke iskemik sebanyak 9 orang (45\%) dan tidak stroke sebanyak 11 orang (55\%). Gambaran karakteristik pasien stenosis arteri ekstrakranial ditampilkan pada Tabel 1 dan 2.

Tabel 1. Distribusi karakteristik pasien stenosis arteri ekstrakranial di RSUP M. Djamil Padang

\begin{tabular}{lc}
\multicolumn{1}{c}{$\begin{array}{c}\text { Karakteristik } \\
(\mathbf{n = 2 0 )}\end{array}$} & \multicolumn{1}{c}{$\begin{array}{c}\text { Frekuensi } \\
\mathbf{n}(\%)\end{array}$} \\
\hline Umur & $56 \pm 99,8(37-71)$ \\
\hline Jenis Kelamin & $8(40)$ \\
-Laki-Laki & $12(60)$ \\
-Perempuan & \\
\hline Morfologi Plak & $11(55)$ \\
-Nonulcerated & $9(45)$ \\
-Ulcerated & $11(55)$ \\
\hline Kejadian Stroke & $9(45)$ \\
-Tidak Stroke & \\
-Stroke Iskemik &
\end{tabular}

Dilakukan analisis bivariat untuk mencari hubungan morfologi plak dengan kejadian stroke iskemik. Hasil uji statistik didapatkan hubungan yang bermakna antara kejadian stroke iskemik dengan morfologi plak $(p=0,02)$, morfologi plak ulcerated 5 kali lebih beresiko untuk kejadian stroke iskemik daripada nonulcerated $(R R=5)$. Hubungan morfologi plak dengan kejadian stroke iskemik ditampilkan pada Tabel 2.
Tabel 2. Hubungan morfologi plak dengan kejadian stroke iskemik

\begin{tabular}{|c|c|c|c|c|c|c|}
\hline \multirow{3}{*}{$\begin{array}{l}\text { Morfologi } \\
\text { plak }\end{array}$} & \multicolumn{4}{|c|}{ Kejadian Stroke } & \multirow{3}{*}{$\mathbf{P}$} & \multirow{3}{*}{$\mathbf{R R}$} \\
\hline & \multicolumn{2}{|c|}{$\begin{array}{c}\text { Tidak } \\
\text { stroke }\end{array}$} & \multicolumn{2}{|c|}{$\begin{array}{c}\text { Stroke } \\
\text { iskemik }\end{array}$} & & \\
\hline & f & $\%$ & $f$ & $\%$ & & \\
\hline Nonulcerated & 9 & 81,8 & 2 & 18,2 & 0,022 & 5 \\
\hline Ulcerated & 2 & 22,2 & 7 & 77,8 & & \\
\hline Jumlah & 11 & 55,0 & 9 & 45,0 & & \\
\hline
\end{tabular}

\section{PEMBAHASAN}

Stroke merupakan penyakit kegawatdaruratan neurologi yang bersifat akut dan salah satu penyebab kecacatan dan kematian tertinggi dibeberapa negara didunia. Persentase stroke iskemik lebih tinggi diandingkan stroke hemoragik. ${ }^{17,18}$ Laporan American Heart Association (AHA) tahun 2016 mendapatkan stroke iskemik mencapai $87 \% .{ }^{19}$ Beberpa mekanisme yang dapat menjelaskan peningkatan resiko kejadian stroke iskemik adalah penurunan aliran darah otak yang disebabkan oleh stenosis ataupun tromboemboli. ${ }^{1}$

Pada dasarnya proses terjadinya stroke iskemik diawali oleh adanya sumbatan pembuluh darah oleh trombus. Trombus terbentuk oleh adanya proses aterosklerosis pada arkus arkus aorta, arteri karotis, maupun pembuluh darah serebral. Proses ini diawali oleh cedera endotel dan inflamasi yang mengakibatkan terbentuknya plak pada dinding pembuluh darah. $^{18,20}$

Hasil penelitian ini menunjukkan bahwa pasien yang menderita sroke iskemik lebih banyak ditemukan pada pasien stenosis aretri ekstrakranial dengan plak ulcerated (77,8\%) dibandingkan dengan yang nonulcerated (18,2\%). Hasil uji statistic Chi-squere diperoleh nilai $\mathrm{p}=0,02$ dan $\mathrm{RR}=5$. Didapatkan hubungan yang bermakna antara kejadian stroke iskemik dengan morfologi plak. 
Penelitian ini sesuai dengan penelitian Yang et al (2016) yang menyatakan bahwa morfologi plak berhubungan dengan stroke iskemik. ${ }^{21}$ Begitu juga dengan penelitian Singh et al (2015) menemukan bahwa plak ulcerated berhubungan dengan dengan kejadian stroke iskemik. ${ }^{2}$

Morfologi plak yang dinilai dari segi ulcerated dan nonulcerated plak pada stenosis arteri ekstrakranial menentukan perjalanan klinis dari stenosis itu sendiri. Permukaan plak yang kasar dan tidak stabil menyebabkan trombus dapat lepas dan menjadi emboli. $^{21}$

Penelitian ini tidak menggali semua faktor-faktor yang mempengaruhi kejadian stroke iskemik, hanya morfologi plak pada pasien yang sudah dikenal menderita stenosis arteri ekstrakranial. sedangkan faktor resiko lain tidak diteliti karena keterbatasan waktu dan kemampuan dari peneliti.

\section{SIMPULAN}

Terdapat hubungan yang bermakna antara morfologi plak pada stenosis arteri ekstrakranial dengan kejadian stroke iskemik. Morfologi plak berupa plak ulcerated lima kali beresiko lebih tinggi untuk kejadian stroke iskemik dibandingkan nonulcerated.

\section{KONFLIK KEPENTINGAN}

Tidak ada konflik kepentingan

\section{UCAPAN TERIMA KASIH}

Terima kasih kepada Bagian Neurologi RSUP Dr. M Djamil Padang dan kepada semua pihak yang telah memberikan motivasi, bimbingan, dan bantuan kepada penulis dalam menyelesaikan tulisan ini.

\section{DAFTAR PUSTAKA}

1. Harris $S$, Kurniawan $M$, Mesiano $T$, editor (penyunting). Ultrasonologi Neurovaskular pada Stroke. Jakarta: Fakultas Kedokteran Universitan Indonesia; 2015.

2. Singh TD, Kramer CL, Mandrekar J, Lanzino G, Rabinstein AA. Asymptomatic carotid stenosis: risk of progression and development of symptoms. Cerebrovasc Dis. 2015; 40: 236-43.
3. Mizukami H, Shimizu T, Maki F, Shiraishi M, Hasegawa Y. Progression of intracranial major artery stenosis is associated with baseline carotid and intracranial atherosclerosis. $\mathrm{J}$ Atheroscler Thromb. 2015;22:183-90.

4. Eckstein H, Kunhl A, Dorfler A, Kopp I, Lawall H, Ringlob $P$. The diagnosis, treatment and follow-up of extracranial carotid stenosis. Dtsch Arztebl Int. 2013; 110:468-76.

5. Thammongkolchai T, Riaz A, Sundararajan S. Carotid stenosis role of plaque morphology in recurrent stroke risk. Stroke. 2017; 48:e197-e99.

6. Naylor AR, Ricco JB, de Borst GJ, Debus S, de Haro J, Halliday A, et al. Editor's choiced management of atherosclerotic csarotid and vertebral artery disease: 2017 clinical practice guidelines of the European Society for Vascular Surgery (ESVS). Eur J Vasc Endovasc Surg 2018; 55:3-81.

7. Wendorff C, Wendorff $\mathrm{H}$, Pelisek J, Tsantilas $\mathrm{P}$, Zimmermann A, Zernecke A, et al. Carotid plaque morphology is significantly associated with sex, age, and history of neurological symptoms. Stroke 2015;46:3213-9.

8. Truijman MTB, Kooi ME, Van Dijk AC, De Rotte AAJ, Kolk AGV, Liem MI, et al. Plaque At RISK (PARISK): prospective multicenter study to improve diagnosis of high-risk carotid plaques. I. J. of Stroke. 2014; 9:747-54.

9. Lei C, Wu B, Liu M, Chen Y. Risk factors and clinical outcomes associated with intracranial and extracranial atherosclerotic stenosis acute ischemic stroke. J Stroke Cerebrovasc Dis 2014; 23:1112-7.

10. Hao Z, Zhang Y, Li Y, Zhao J, Zhao Y, Qiu J, Zhao $\mathrm{R}$, et al. The association between ideal cardiovascular health metrics and extracranial carotid artery stenosis in a Northern Chinese population: a cross-sectional study. Sci Rep. 2016. $6: 31720$

11. Jonas, D, Feltner C, Amick H, Serldan S, Zheng Z, Watford D, et al. Screening for asymptomatic carotid artery stenosis: a systematic review and meta-analysis for the U.S. preventive services task force. Ann Intern Med. 2014;161:336-46. 
12. Madieke IL, Fiona K, Leo HB, Aad VL, Bram FC, Aart JN, et al. Investigations of carotid stenosis to identify vulnerable atherosclerotic plaque and determine individual stroke risk. Circ J. 2017;8:: 1246-53.

13. Muscari A, Bonfiglioli A, Magalotti D, Puddu GM, Zorzi V, Zoli M. Prognostic significance of carotid and vertebral ultrasound in ischemic stroke patients. Brain and Behavior. 2016; 6(6): 1-8

14. Paraskevas KI, Mikhailidis DP, Veith FJ, Spence JD. Definition of best medical treatment in asymptomatic and symptomatic carotid artery stenosis. Angiology 67. 2016:411-9.

15. Wang D, Weng J, Jin C, Ji R, Wang A, Li X, et al. Asymptomatic extracranial artery stenosis and the risk of cardiovascular and cerebrovascular diseases. Sci Rep 6. 2016:33960.

16. Huynh TT, Broadbent KC, Jacob AD, James S, Erasmus JJ. Screening for carotid artery stenosis. Semin Roentgeno. 2015; 150:127-38.

17. Compter A, Worp VHB, Schonewille WJ, Vos JA, Boiten J, Nederkoorn PJ, et al. Stenting versus medical treatment in patients with symptomatic vertebral artery stenosis: a randomised open-label phase 2 trial. Lancet Neurol. 2015;14:606-14.

18. Rasyid A, Harris S, Kurniawan M, Mesiano T. Buku Ajar Neurologi: Stroke Iskemik. Jakarta: Fakultas Kedokteran Universitas Indonesia; 2017.

19. Benjamin EJ, Blaha MJ, Chiuve SE, Chusman M, Das SR, Deo R, et al. Heart disease and stroke statistics-2017 update: a report from the American Heart Association. Circulation. 2017;135:e146.

20. Szikra P, Boda K, Rarosi F, Thury A, Barzó P, Németh $\mathrm{T}$, et al. Aortic arch and common carotid artery plaques with soft components pose a substantial risk of cerebral embolization during carotid stenting. Interv Neuroradiol. 2016; 22: 438-44.

21. Yang QH, Shen W, Jia X. D, Ru J. P, Du W. Z. Correlation of ultrasound detection of carotid atherosclerosis plaque with ischemic cerebral stroke. J. of Hainan Medical University. 2016;; 22(15):153-5. 